\title{
XII
}

\section{SENTIDOS E CONCEPÇÕES DE PROFISSIONALIZAÇÃO NAS MEDIDAS SOCIOEDUCATIVAS: ANÁLISE DAS POLÍTICAS DE SEMILIBERDADE DO ESTADO DO RIO DE JANEIRO*}

Adriana Soares Barbosa ${ }^{1}$

Constantemente a mídia veicula notícias sobre o aumento da violência no país, reafirmando o ponto de vista da periculosidade dos jovens autores de ato infracional, ainda vistos como "menores infratores", incorrigíveis e delinquentes por essência. Muito dessa opinião alimenta, também, o estereótipo do bandido na figura do jovem negro e morador de favela, impulsionando a ideia de que não merecem respeito ou trégua, sendo impossível pensá-los como cidadãos.

Sem a ideia de cidadania para todos, justifica-se a falta de importância dada pelo Estado em relação à garantia dos direitos para crianças e jovens moradores das periferias, dificultando o acesso e permanência de alguns à escola, ao lazer, a cultura, ao esporte, a profissionalização e à proteção em relação ao trabalho. Por outro lado, cada vez mais o Estado se faz presente em ações punitivas e violentas nas favelas, afetando diretamente o jovem negro e periférico, que engrossa os sistemas prisionais e socioeducativos em todo o país.

No que tange aos jovens autores de ato infracional, o Estatuto da Criança e do Adolescente (ECA) prevê medidas socioeducativas ${ }^{2}$. Alguma dessas medidas restringem ou privam a liberdade através da internação e da semiliberdade, mas ainda que o direito de ir e vir estejam limitados ou impedidos, os jovens devem ter todos os outros direitos garantidos.

Além de garantir a escolarização, as instituições executoras das medidas socioeducativas necessitam possibilitar a preparação do jovem para o mundo do trabalho, conforme o estabelecido na Constituição Federal, que prevê a to-

${ }^{*}$ DOI - 10.29388/978-65-86678-41-3-0-f.247-266

${ }^{1}$ Mestre em Educação pela UFF e Pesquisadora do Núcleo de Estudos e Documentação sobre Educação de Jovens e Adultos - NEDEJA e do Grupo de Trabalho e Estudos sobre Políticas de Restrição e Privação de liberdade da UFF. Psicóloga do Departamento Geral de Ações Socioeducativas (Degase).

${ }^{2}$ Advertência, prestação de serviços à comunidade, liberdade assistida, semiliberdade e internação. 
dos o "direito à educação, visando ao pleno desenvolvimento de sua pessoa, preparo para o exercício da cidadania e qualificaşão para o trabalbo" (BRASIL, 1988, art. 205, grifo nosso).

Assim, nesta pesquisa, que diz respeito aos resultados de dissertação de mestrado defendida em 2020 no Programa de Pós-graduação em Educação da Universidade Federal Fluminense, propomos compreender os sentidos e concepções de "profissionalização" nas propostas de políticas para os jovens que estão em cumprimento de medida socioeducativa de semiliberdade no estado do Rio de Janeiro.

Iniciamos a pesquisa com o estudo da legislação nacional, principalmente analisando a Constituição Federal (1988), o ECA (Lei no 8.069/90), a Lei de Diretrizes e Bases da Educação - LDB (Lei no 9.394/96) e o Sistema Nacional de Atendimento Socioeducativo - SINASE (Lei no 12.594/2012). No âmbito dos documentos estaduais, foram analisados sobretudo o Plano de Atendimento Socioeducativo do estado do Rio de Janeiro - PASE (DEGASE, 2010a), sancionado pelo Decreto $n^{\circ} 42.715 / 2010$ e o Projeto Político Institucional PPI (DEGASE, 2010b) do Departamento Geral de Ações Socioeducativas (DEGASE) ${ }^{3}$.

Em âmbito local foram analisados documentos produzidos pelas unidades socioeducativas de semiliberdade do estado do Rio de Janeiro, os Centro de Recursos Integrados de Atendimento ao Adolescente (CRIAAD): Projeto Político Pedagógico (PPP) do ano de 2019 de cada CRIAAD; e Relatórios pedagógicos mensais dos CRIAADs dos meses de março, abril e maio de 2019.

Ademais, realizamos pesquisa de campo, tendo consistido em participação das reuniões de apresentação dos Projetos Políticos Pedagógicos dos CRIAADs no ano de 2019. Para a análise, levamos em conta a diversidade de questões que emergiram no momento em que o PPP foi compartilhado entre as equipes das unidades e a equipe gestora do DEGASE.

\section{Restrição e privação de liberdade de jovens no Brasil e no estado do Rio de Janeiro}

Segundo Câmara (2017), durante o período colonial, a infância e a juventude pobres que não servissem como força de trabalho, órfã, abandonada ou infratora poderiam ser recolhidas por instituições filantrópicas ou casas cor-

\footnotetext{
${ }^{3}$ Órgão responsável pela execução das medidas socioeducativas de internação e semiliberdade no estado do Rio de Janeiro.
} 
recionais. A partir do século XIX foram se estruturando as formas de tratamento do Estado para a infância e juventude pobres, dividindo-se esse processo, de acordo com Bazílio (1996), em três fases: a primeira é filantrópica e assistencialista; a segunda é tutelar ou da doutrina da situação irregular ${ }^{4}$ e a terceira é da doutrina da proteção integral ${ }^{5}$.

Do período do Brasil Imperial até início do século XX, era vigente o critério penal indiferenciado. Segundo Rodrigues (2017), crianças e jovens autores de ato infracional eram considerados criminosos e podiam ser presos, de acordo com o discernimento ${ }^{6}$. Já a criança abandonada podia ficar sujeita a caridade, predominando a prática de internar crianças pobres para prevenir que se tornassem futuros marginais. A segunda fase inicia com a criação do primeiro Juizado de Menores, em 1923, e se estende até o fim dos anos 1980. Segundo Costa A. C. (2006), a maior perversidade deste período consistia no tratamento jurídico dos casos sociais e da falta de garantia processual dos casos de jovens autores de ato infracional.

A terceira fase se inicia no final dos anos 1980 com a promulgação da Constituição Federal de 1988, que no seu art. 227, imputa ao mundo adulto a responsabilidade de proteger a criança e o jovem, assim como reconhece o princípio de prioridade absoluta na defesa de seus direitos. Segundo Julião e Oliveira (2017), a grande contribuição da Constituição para a criança e o jovem foi ter elevado esse público ao status de cidadão.

Assim, através do Estatuto da Criança e do Adolescente, a doutrina da proteção integral foi inaugurada no Brasil e na América Latina, desenvolvendo a concepção já trazida pela Constituição Federal de que crianças e adolescentes são pessoas em desenvolvimento.

O ECA determina que o adolescente deve responder por atos que transgridam às leis penais de forma diferente dos adultos. Do art. 103 ao 105, o Estatuto define o ato infracional como a conduta análoga ao crime ou contravenção penal e que os menores de 18 anos são inimputáveis penalmente, sendo as medidas socioeducativas aplicadas aos que possuem de 12 a 18 anos incompletos, mas o cumprimento da medida pode se dar até 21 anos, devendo-se considerar a sua idade no momento em que ocorreu o ato infracional.

\footnotetext{
4 Advinda do termo "menor em situação irregular", que foi consagrado com o Código de Menores de 1979.

${ }^{5}$ Fundamentada pela Convenção Internacional sobre os Direitos da Criança que foi aprovada pela Resolução 44/25 da Assembleia das Nações Unidades em 20 de novembro de 1989.

${ }^{6} \mathrm{O}$ critério psicológico do discernimento estava presente no Código Criminal do Império (1830) e no Código Penal Republicano (1890).
} 
No que se refere à medida de semiliberdade:

O regime de semiliberdade pode ser determinado desde o início, ou como forma de transição para o meio aberto, possibilitada a realização de atividades externas, independentemente de autorização judicial.

$\int 1^{\circ}$. É obrigatória a escolarização e a profissionalização, devendo, sempre que possível, ser utilizados os recursos existentes na comunidade.

$\int 2^{\circ}$. A medida não comporta prazo determinado, aplicando-se, no que couber, as disposições relativas à internação (BRASIL, 1990, art. 120).

A medida de semiliberdade impõe algumas limitações do jovem ao convívio familiar e à comunidade, implicando em sua institucionalização, assim como a internação. $\mathrm{Na}$ internação como na semiliberdade, as atividades externas são previstas, porém, no primeiro caso, o juiz pode impedir a realização dessas atividades e, no segundo caso, não.

O que melhor diferencia a semiliberdade da internação é a obrigatoriedade da realização das atividades externas. Dessa forma, os jovens devem ser atendidos em suas necessidades na comunidade, através da sua participação na escola, nos cursos, nos postos de saúde e outros ambientes externos, contribuindo para o exercício da sua cidadania.

No que se refere à relação com o Sistema de Garantia de Direitos (SGD), a semiliberdade possui a obrigação de se articular com a rede existente na localidade em que a unidade está localizada.

A medida de semiliberdade e as outras medidas mais brandas são uma aposta do ECA para a superação do modelo de apartação social do jovem em conflito com a lei. Diferente da internação, as outras medidas socioeducativas possibilitam a participação dos jovens a convivência comunitária e que o sistema socioeducativo funcione como catalisador das políticas em rede.

Para atender o ECA, o Departamento Geral de Ações Socioeducativas (DEGASE) foi criado em 26/01/1993 através do Decreto $n^{\circ} 18.493$, como um órgão vinculado à Secretaria de Estado de Justiça ${ }^{7}$ do estado do Rio de Janeiro, responsável pela execução das medidas socioeducativas. Atualmente, atende as medidas de internação e semiliberdade, estando às medidas de meio aberto sob a responsabilidade dos municípios.

O DEGASE possui sete unidades de internação e 15 CRIAADs lo-

\footnotetext{
7 Atualmente o DEGASE encontra-se, desde 2008, vinculado à Secretaria de Estado de Educação (SEEDUC).

${ }^{8}$ Escola João Luiz Alves, CAI Belford Roxo, CENSEs Ilha, Dom Bosco, Prof. Antônio Carlos Gomes da Costa, Volta Redonda e Campos.
} 
calizados na Penha, Bangu, Bonsucesso, São Gonçalo, Niterói, Santa Cruz, Macaé, Cabo Frio, Barra Mansa, Volta Redonda, Duque de Caxias, Campos, Nilópolis, Nova Iguaçu e Teresópolis.

Além do ECA, outro documento norteador da atual política socioeducativa é o Sistema Nacional de Atendimento Socioeducativo (SINASE), através da Resolução no 119/2006 (CONANDA, 2006) e instituído pela Lei 12.594/2012 (BRASIL, 2012), sendo definido como um conjunto ordenado de princípios, regras e critérios que envolvem a execução das medidas socioeducativas, abrangendo todo o país.

A partir do SINASE é apresentado um novo modelo de gestão de atendimento ao jovem em cumprimento de medida socioeducativa, que, segundo Pereira e Gomes (2017), possui como características a multidimensionalidade, a interinstitucionalidade e a interdisciplinaridade.

A multidimensionalidade compreende a gestão compartilhada entre as esferas federais, estaduais e municipais. A interinstitucionalidade diz respeito às ações do judiciário, do legislativo, do executivo e da participação popular, através dos conselhos. A interdisciplinaridade é representada pela construção e reconstrução do conhecimento gerado na prática de gestores, equipes técnicas e agentes socioeducativos.

\section{As políticas de profissionalização em âmbito nacional}

A nossa Carta Magna representa, em relação a todas as Constituições que já tivemos, um grande avanço em termos de direitos, sendo chamada por muitos de Constituição Cidadã. Ela traz o conceito de educação como um direito de todos, sendo um direito público e subjetivo (BRASIL, 1988, art. 208, $\$ 1^{\circ}$ ). Dessa forma, a educação passa a ser reconhecida não mais como um benefício, mas sim como um direito de todos, incluindo os jovens em cumprimento de medida socioeducativa.

Dois anos depois da Constituição Federal, o Estatuto da Criança e do Adolescente (ECA) foi promulgado. Além de tratar o direito à educação, o ECA, no capítulo $\mathrm{V}$, evidencia o "direito à profissionalização" e "a proteção no trabalho", concebendo como aspecto desse direito, a condição peculiar de pessoa em desenvolvimento dos jovens menores de 18 anos.

Importante destacar o sentido dado à "profissionalização" no ECA, que é percebida como a ação de profissionalizar, conforme definido por Fidalgo e Machado (2000), apresentando um caráter de aprendizagem de uma deter- 
minada profissão, que possui critérios de formação, carreira, direitos trabalhistas e progresso dentro de uma atividade profissional. O Estatuto trata também do trabalho educativo, da formação técnico profissional, do trabalho protegido, assegura os direitos trabalhistas e previdenciários, bem como, versa sobre o jovem aprendiz.

O ECA proíbe, no art. 60, "qualquer trabalho a menores de 16 anos de idade, salvo na condição de aprendiz a partir dos 14". A partir da Lei no 11.180/2005, em seu art. 18, o jovem aprendiz é compreendido como a pessoa entre 14 e 24 anos que celebra contrato de aprendizagem, definido como um contrato de trabalho especial, com garantias específicas pelo Decreto $\mathrm{n}^{\circ}$ $9.579 / 2018$.

Segundo Paiva (2009), ao admitir o trabalho do jovem de 14 anos na condição de aprendiz, a Constituição acaba por encobrir os desvios sobre como o trabalho se faz no Brasil, que, sabemos, não respeita a legislação referente à profissionalização e trabalho dos menores de 18 anos e nem mesmo a legislação trabalhista vigente para os adultos.

Pode-se dizer que no Brasil o trabalho infantil só deixará de existir quando for encarado como problema, porque até então tem sido encarado como solução, admitindo-se a concepção social que considera melhor que a criança, o adolescente, o jovem trabalhem, do que acabem, pelo ócio, caindo na marginalidade. Evidentemente que esse modo de pensar não se aplica a todas as classes sociais, mas apenas às populações pobres, vistas como marginais na essência, e às quais, diante de "oportunidades", passam a "desenvolver essa potência" (PAIVA, 2009, p.184).

Ainda que possamos problematizar as relações de trabalho no que se refere ao jovem aprendiz, para Costa (2019), o Programa Jovem Aprendiz se diferencia das demais políticas de profissionalização para a juventude, porque, por meio dela é possível a inserção imediata do jovem no mercado formal de trabalho, além de contribuir para a ampliação da escolaridade, pelo menos até o nível médio, pois determina a continuidade dos estudos ou que tenha concluído essa etapa da educação básica.

Se o ECA diz respeito à garantia dos direitos das crianças e do adoles cente, é a Lei no 9.394/1996, que dispõe sobre a Lei de Diretrizes e Bases da Educação (LDB), que organiza o sistema nacional de ensino no Brasil. O capítulo III da LDB trata da educação profissional e tecnológica (EPT), definindo-a como uma modalidade que abrange cursos de qualificação, habilitação técnica e 
tecnológica, e de pós-graduação, integrando-se com os diferentes níveis e modalidades da educação e às dimensões do trabalho, da ciência e da tecnologia. Assim, a EPT pode se articular com a modalidade da educação de jovens e adultos, a educação básica no nível do ensino médio e nos níveis de graduação e pós-graduação.

Os cursos de qualificação profissional incluem os cursos de capacitação profissional, aperfeiçoamento e atualização de trabalhadores em todos os níveis de escolaridade, podendo se integrar aos itinerários formativos do sistema educacional ou associar-se aos cursos de livre oferta. Estes, conforme o art. 42 da LDB, podem ser abertos à comunidade, não condicionados ao nível de escolaridade, sem carga horária definida.

Sobre a educação profissional de nível médio, a LDB estabelece que poderá ser ofertada "articulada", para os que estão cursando o ensino médio ou "subsequente", para os que já concluíram. Sendo "articulada", pode ocorrer de forma "integrada" na mesma instituição de ensino com matrícula única ou "concomitante" com matrículas distintas na mesma instituição ou instituição distinta. Sendo "subsequente" é ofertada para os que concluíram essa etapa da educação básica anteriormente (BRASIL, 1996, art. 36-B, I, II; art. 36-C, I, II, a, $\mathrm{b}, \mathrm{c})$.

Dessa forma, assim como todos os outros jovens do país, os que se encontram cumprindo uma medida socioeducativa possuem os mesmos direitos garantidos por leis, em relação ao que se refere à sua profissionalização. Contudo, por encontrarem-se em situação de vulnerabilidade, apresentam outras garantias que são especificadas pelo SINASE.

No eixo educação, o SINASE (CONANDA, 2006) estabelece que as unidades de internação e semiliberdade precisam garantir o acesso a todos os níveis da educação formal, o que implica que os programas devem se preparar para atender as necessidades dos jovens da educação básica em nível fundamental e médio, bem como, se necessário, em relação a entrada no nível superior de ensino. O SINASE estabelece, ainda, que a formação profissional do jovem em cumprimento de medida socioeducativa se dá no âmbito da educação profissional, conforme estabelecido pela LDB, em programas de formação inicial e continuada, tal qual, na educação profissional técnica de nível médio ou superior.

Segundo Fidalgo e Machado (2000), substitui-se o termo formação profissional por educação profissional para que se retire a ênfase que é dada ao "saber fazer" e a visão instrumental e tecnicista de modelação dos indivíduos dos cursos que visem à profissionalização. Pretende-se, com isso, fortalecer a con- 
cepção de uma educação para o desenvolvimento integral da pessoa que se prepara profissionalmente.

O SINASE prevê, ainda, que as unidades socioeducativas necessitam encaminhar os jovens ao mercado de trabalho, inserindo-os no mercado formal, em estágios remunerados, nos programas de jovem aprendiz e nas atividades de geração de renda, promovendo ações de orientação, conscientização e capacitação sobre direitos e deveres em relação à previdência social (CONANDA, 2006, p. 64).

O documento estabelece que as unidades socioeducativas devem possibilitar o desenvolvimento das competências presentes no documento "Relatório para a UNESCO da Comissão Internacional sobre a Educação para o Século XXI", coordenado por Jacques Delors. Este documento compreende que o princípio geral da ação educativa nos países periféricos deve atender a uma sociedade em constante mudança, organizando-se em torno de quatro aprendizagens (aprender a conhecer, aprender a fazer, aprender a viver juntos e aprender a ser), também chamadas de saberes, que são replicadas em vários documentos educacionais do Brasil na época.

[...] possibilitar aos adolescentes o desenvolvimento de competências e habilidades básicas, específicas e de gestão e a compreensão sobre a forma de estruturação e funcionamento do mundo do trabalho. Juntamente com o desenvolvimento das competências pessoal (aprender a ser), relacional (aprender a conviver) e a cognitiva (aprender a conhecer), os adolescentes devem desenvolver a competência produtiva (aprender a fazer), o que além de sua inserção no mercado de trabalho contribuirá, também, para viver e conviver numa sociedade moderna (CONANDA, 2006, p. 64).

Observa-se que para este documento os quatro saberes estão interligados, compreendendo que é preciso não mais estar qualificado de forma específica, mas é preciso desenvolver competências que permitirão ao jovem a sua inclusão em uma sociedade global e complexa. Por este caminho, pensa-se que é possível construir uma proposta de educação que dê conta de preparar as pessoas para a fase atual do capitalismo de acumulação flexível, promovendo a autonomia dos pobres para retirá-los da situação de vulnerabilidade, porém naturalizando as causas da pobreza, eliminando as tensões sociais, sem precisar mexer nas bases capitalistas ou questioná-la (RUMMERT; ALGEBAILE; VENTURA, 2013). 
Se o documento operacional do SINASE (CONANDA, 2006) busca dar ênfase à educação profissional, a Lei 12.594/2012 não faz menção à educação, apresentando um capítulo que resolve sobre a capacitação para o trabalho (BRASIL, 2012, art. 76, 77, 78, 79e 80), estabelecendo a oferta de vagas de aprendizes e cursos profissionalizantes por meio de parcerias dos órgãos executores da medida socioeducativa com as escolas do Serviço Nacional de Aprendizagem Industrial (SENAI), Serviço Nacional de Aprendizagem Comercial (SENAC), Serviço Nacional de Aprendizagem Rural (SENAR) e Serviço Nacional de Aprendizagem do Transporte (SENAT).

As escolas do SENAI poderão ofertar vagas aos usuários do Sistema Nacional de Atendimento Socioeducativo (SINASE) nas condições a serem dispostas em instrumentos de cooperação celebrados entre os operadores do SENAI e os gestores dos Sistemas de Atendimento Socioeducativos locais (BRASIL, 2012, art. 76, $\$ 1^{\circ}$, grifo nosso).

Os artigos subsequentes, referentes às parcerias com o SENAC, SENAR e SENAT, seguem o mesmo padrão de redação do art. 76 e, embora a Lei utilize o verbo poder, segundo MPMG (2014), o direito a profissionalização corresponde a um direito fundamental. Logo, o verbo poder não se refere a uma opção, de modo que as outras normativas como o ECA e a Constituição dão sustentação a interpretação de que a oferta de cursos e do jovem aprendiz aos jovens do sistema socioeducativo são obrigatórias ao Sistema $\mathrm{S}$.

Desse modo, o SINASE propõe aos jovens em cumprimento de medida socioeducativa uma educação profissional baseada no saber fazer e na capacitação profissional, visando cursos paralelos ao processo educacional e demonstrando a influência da teoria do capital social nas políticas de profissionalização para o sistema socioeducativo.

Para Motta (2012), o capital social é definido como a capacidade de uma sociedade para estabelecer laços de confiança e a cooperação com vistas à produção de bens coletivos, incorporando uma dimensão humana a um processo econômico. Isto é, a teoria do capital social atribui um caráter mais humanizado ao capitalismo, porém através de um processo de educação para o conformismo às regras do trabalho precarizado. 


\section{As políticas de profissionalização do DEGASE para os jovens em cumprimento de medida socioeducativa de semiliberdade}

O Plano de Atendimento Socioeducativo (PASE/2010) é um documento do governo do estado do Rio de Janeiro, sendo fundamental na compreensão das ações do DEGASE, apresentando quatro linhas de ação: políticas sociais básicas; políticas de assistência social; políticas de proteção especial; políticas de promoção e defesa dos direitos humanos no marco da "proteção jurídico-social” (DEGASE, 2010a, art. 2º, I,II, III, IV).

Seu principal objetivo é a estruturação de políticas, integrando as instituições públicas, estaduais, municipais e as organizações não governamentais, buscando manter um estreito alinhamento conceitual, estratégico, operacional e essencial com as diretrizes e bases do SINASE.

A vista disso, o DEGASE apresentou outro documento no mesmo ano, o Projeto Político Institucional (PPI) que tem como fundamento o PASE/2010. O PPI funciona como formulador de diretrizes para que a política socioeducativa e a doutrina da proteção integral estejam presentes na elaboração dos projetos do órgão e das unidades socioeducativas.

Com base no SINASE (CONANDA, 2006), o PPI se aprofunda na visão do Relatório de Jaques Delors, tendo como princípio pedagógico da medida socioeducativa o desenvolvimento das competências intrínsecas aos quatro pilares, que associa à profissionalização ao "saber fazer". Como vimos, essa concepção de profissionalização acaba por buscar a adaptação do jovem à sociedade desigual. Promete possibilidades de continuidade da escolarização, mas permite que se desenvolvam competências que visam à inclusão no trabalho flexível dentro da sociedade de classes, a qual estamos submetidos.

Todos os PPP das unidades se baseavam no PPI do DEGASE. Há uma enorme expectativa de que a (re)socialização se dê pela educação e profissionalização. Todas as unidades relatam, apesar de dificuldades pontuais, a parceria com as Secretarias de Educação locais para a efetivação da escolarização, mas a profissionalização ainda é o grande desafio da maioria dos CRIAADs, que mencionam, frequentemente, a necessidade de retomada de alguma parceria perdida ou não consumada em anos anteriores.

Além dos PPP das unidades, outro documento que possibilitou verificar a dinâmica de cursos existentes nas unidades socioeducativas foi o Relatório Pedagógico dos meses de janeiro, fevereiro e março de 2019 de cada unidade. Estes documentos foram divididos em duas categorias (região metropolitana e 
interior do estado) e subdivididos em outras duas categorias (ambiente interno e ambiente externo). Os que se encontram na região metropolitana compreendem os CRIAADs localizados na capital do estado ${ }^{9}$, na Baixada Fluminense ${ }^{10}$ e nos municípios de Niterói e São Gonçalo. No interior localizam todos os outros CRIAADs ${ }^{11}$.

Mesmo havendo maior variedade de turmas nos cursos em ambiente externo, o alcance em termos quantitativos de jovens matriculados nos cursos em ambiente interno é bem maior, tanto na região metropolitana como no interior do estado. De um total de 316 participantes em semiliberdade no estado do Rio de Janeiro, 75 (24\%) participavam de cursos externos, isto é, na comunidade, e $241(76 \%)$ em ambiente interno, isto é, no interior dos CRIAADs.

No que se refere à análise das regiões, observamos que dos 119 participantes da educação profissional em semiliberdade no interior do estado, 83 $(70 \%)$ realizaram os cursos internamente. A situação das unidades da região metropolitana é um pouco mais inquietante, por se tratar de semiliberdade; dos 197 participantes dos cursos profissionalizantes, 158 (80,2\%) realizaram esses cursos em ambiente interno.

Frequentemente, a lógica dos cursos dentro da unidade de semiliberdade pode obedecer à demanda por diminuir o tempo ocioso do jovem na unidade, pois nem sempre é possível identificar nos relatórios o período do curso, se há certificação e quantos alunos concluíram. Enquanto que em relação aos cursos externos fica implícita a certificação dos jovens, além de inseri-los em espaços próprios ao desenvolvimento da juventude. Ademais, a prioridade do DEGASE na participação dos jovens em cumprimento de semiliberdade nos cursos em ambiente interno permite que a lógica da internação se perpetue, contrariando o disposto no ECA, que prioriza os recursos existentes na comunidade (BRASIL, 1990, art. 120, $\$ 1^{\circ}$ ).

Apesar das medidas socioeducativas atenderem jovens até 21 anos, nenhum deles realizava curso em nível superior. Dos 315 participantes em cursos nos CRIAADs, apenas quatro (1\%) realizavam cursos em nível técnico, um no interior do estado e os outros dois na região metropolitana. Todos os quatro realizavam a educação profissional articulada ao ensino médio. Três deles, a educação profissional ocorria em instituições privadas ou público-privadas, enquanto o ensino médio se dava em instituições públicas e o outro realizava a

\footnotetext{
${ }^{9}$ Penha, Santa Cruz, Bangu e Bonsucesso.

${ }^{10}$ Nova Iguaçu, Duque de Caxias e Nilópolis.

${ }^{11}$ Barra Mansa, Campos dos Goytacazes, Cabo Frio, Macaé, Teresópolis e Volta Redonda.
} 
educação profissional na mesma instituição pública em que cursava o ensino médio.

Por outro lado, 99\% realizavam cursos de formação profissional de livre oferta, que atendem a todos os níveis de escolaridade, alguns com carga horária inferior a 160 horas. Nenhum deles abrangia os cursos de qualificação profissional integrados aos itinerários formativos do sistema educacional.

Os cursos na área da informática são os que constam de maior quantitativo nas unidades socioeducativas de semiliberdade, principalmente na região metropolitana $(50 \%)$.

$\mathrm{Na}$ tentativa de atender a demanda das novas formas de trabalho, os CRIAADs lançam mão das propostas de curso de informática, buscando que os jovens se adéquem ao trabalho da era informacional. Segundo Costa (2019), o movimento de automação e informatização de alguns setores do mundo do trabalho determinou um processo de complexificação do trabalho simples e, consequentemente, os cursos na área de informática não têm exigido níveis de escolaridade muito altos, sendo considerados como um dos cursos coringas, que atenderia tanto os jovens do ensino fundamental como os de nível médio.

Os cursos de artesanato e horta de duas unidades do interior do estado foram analisados por constarem em seus projetos o objetivo de geração de renda. Contudo, ressaltamos que esses cursos são realizados em ambiente interno, tendo como instrutores funcionários e/ou voluntários. Dessa forma, possivelmente os cursos de artesanato e horta apresentam objetivos mais pedagógicos que propriamente de preparação para o mundo do trabalho, representando juntos $60 \%$ do quantitativo de jovens realizando os cursos no interior do estado ( $23 \%$ de jovens realizando o curso de horta e $32 \%$ de artesanato).

Três CRIAADs atendem jovens do sexo feminino, sendo dois mistos no interior do estado e um exclusivo para meninas na região metropolitana, com um total de 29 jovens no estado do Rio de Janeiro. Dessas, 12 realizavam cursos de artesanato, 3 estavam matriculadas no curso de culinária, 6 no curso de trança e maquiagem e apenas uma delas estava inserida no trabalho educativo em parceria com a prefeitura local.

Conforme podemos observar, os cursos ofertados às meninas dizem respeito à aprendizagem de atividades manuais e cuidados. São atividades que reafirmam o estereótipo que associam tarefas próprias para as mulheres, como as que exigem paciência e minúcia (SOUSA; GUEDES, 2016). Além disso, valoriza a inserção da mulher em atividades e trabalhos informais, em que os tem- 
pos de trabalho podem ser mais parciais para que deem conta da dupla jornada de trabalho.

Através das informações qualitativas contidas nos relatórios, constatamos que as maiores dificuldades em relação às ações de profissionalização são: risco e vulnerabilidade em relação aos territórios dominados por facções ou milícias; alta rotatividade dos adolescentes nas unidades, baixa escolaridade, dificuldades de articulação com a rede de SGD etc.

A situação de risco e vulnerabilidade vivenciada pelos jovens foi o ponto principal apresentado pelas unidades. Essa é uma questão que vem se intensificando e diz respeito à dominação das regiões mais empobrecidas por facções $^{12}$ e milícias ${ }^{13}$ que controlam espaços das cidades, estabelecendo fronteiras e determinando regras de circulação e convivência.

A medida de semiliberdade é a mais afetada por essa lógica, pois os jovens de várias áreas necessitam cumprir a medida em uma determinada localidade, que pode ser de domínio de uma facção e ou milícia diferente da que controla os espaços na localidade em que reside.

Conforme Godoi (2019, p. 190), os jovens em cumprimento de medida socioeducativa encontram-se:

[...] privados de explorar outros espaços que poderiam, igualmente, compor e enriquecer suas redes de relações intersubjetivas para além daquelas que já podem tecer legitimamente, em suas comunidades, impedindo-lhes, portanto, de experimentar a "cidade educativa" de maneira plena e de usufruir dos bens materiais e simbólicos distribuídos e imbricados aos espaços urbanos e, deles e com eles, estabelecer relações construtivas de aprendizagem e formação.

Os CRIAADs ao inserirem os jovens nas atividades externas precisam lidar com as mesmas limitações em termos de circulação e possibilidades e necessitam acionar o SGD para que possam garantir a segurança dos jovens que necessitam fazer uso dos espaços de aprendizagem e formação.

Sobre a alta rotatividade nas unidades de semiliberdade, observamos que dos 616 jovens que passaram por 10 CRIAADs $^{14}$, no período de três me-

\footnotetext{
${ }^{12}$ Grupos que, além de realizarem outros crimes, disputam o controle do tráfico de drogas, constituindo-se em um verdadeiro poder paralelo, com costumes e leis próprias entreos integrantes.(NOVELLINO; OLIVEIRA, 2019).

${ }^{13}$ São organizações criminosas paramilitares, que contam principalmente com policiais, bombeiros, militares e agentes penitenciários (GODOI, 2019).

${ }^{14}$ Sobre os desligamentos foram analisados três CRIAADs do interior e sete na região metropolitana.
} 
ses, 354 se desligaram, correspondendo a 57,5\%. Na região metropolitana, esse quantitativo correspondeu a $55,1 \%$ e no interior do estado o percentual era de $64 \%$. De todos os casos de desligamentos do estado do Rio de Janeiro, 65,8\% se deram por evasões e descumprimentos ${ }^{15}$, correspondendo a uma saída abrupta dos jovens. Já a progressão da medida, em que, possivelmente, as equipes tiveram a possibilidade de planejar com os jovens as ações e acompanhálas, correspondem a um percentual de 17,8\% dos casos.

A alta rotatividade dos jovens afeta a participação nos cursos profissionalizantes em ambiente externo, principalmente, porque o período de inscrição das instituições responsáveis pela profissionalização nem sempre condiz com o período de entrada do jovem na unidade. Assim, do tempo que leva da inscrição até a definição da vaga é comum que o jovem não se encontre mais no CRIAAD ao início do curso.

A baixa escolaridade é outro ponto dificultador no planejamento dos cursos profissionalizantes, pois é muito comum se evidenciar exigências mínimas de escolarização para participação em determinados cursos oferecidos principalmente por instituições externas ou em cursos que visem o trabalho intelectual ou mais valorizado. Esta realidade demonstra que se a escolarização no Brasil se democratizou no acesso, buscou outras formas de selecionar os que realmente conseguem garantir o seu direito à educação.

A escola é a instituição que pode dar ao indivíduo a possibilidade de encarar o mundo com melhores chances de sucesso. É a escola que pode contribuir para uma socialização mais efetiva dos sujeitos. Mas também é a escola que representa um grande obstáculo a ser vencido por grande parte da população que vive a margem da sociedade. É a escola também que muitas vezes expulsa o sujeito, limitando suas chances de alcançar o objetivo desejado, quer seja a obtenção de um certificado para garantir um emprego melhor, ou uma formação acadêmica, ou meramente aprender a ler para garantir uma melhor circulação pela sociedade letrada (JESUS, 2018, p. 113).

Analisar a realidade escolar dos jovens em cumprimento de medida socioeducativa é fundamental para refletirmos sobre a classe social desses jovens e qual o tipo de educação é garantida aos filhos das classes populares. Em uma sociedade desigual em que as oportunidades são diferenciadas, os jovens que se encontram em cumprimento de medida socioeducativa necessitam de maior in-

${ }^{15} \mathrm{~A}$ evasão corresponde à fuga e o descumprimento consiste na recusa em cumprir a medida. 
vestimento para recuperarem os anos de escolarização deixados para trás, devido ao seu histórico de vulnerabilidades.

Outra questão evidenciada nos relatórios é a articulação com a rede de SGD. As unidades pontuam algumas parcerias nos PPP, porém, ao analisarmos os relatórios, constatamos que nem sempre essas parcerias são efetuadas. Além disso, observamos que ao chegar ao sistema socioeducativo, muitos jovens tiveram seus direitos negados e que, na realidade, o SGD não alcança a todos, conforme previsto nas legislações dos sistemas de saúde, educação, justiça, segurança e assistência social.

Sobre a profissionalização dos jovens em semiliberdade, observamos que as instituições públicas ligadas aos governos locais são as que apresentaram maior facilidade de interlocução com os CRIAADs, conseguindo atingir 90 participantes no estado do Rio de Janeiro, num total de 36\%. Em contrapartida, as instituições estaduais e federais (FAETEC e CEFET) representaram um percentual 6,4\% atendendo a 16 jovens em semiliberdade.

Contudo, são as Organizações da Sociedade Civil (OSC) ${ }^{16}$ que atingem o maior número de participação dos jovens nas atividades profissionalizantes em um total de 141, representando $56,4 \%$ de inscritos em seus projetos na área de profissionalização. São oito cursos profissionalizantes, com 85 participantes $(34 \%)$ e o restante inscritos em oficinas de preparação para o mundo do trabalho $(22,4 \%)$.

As OSC são chamadas de "terceiro setor" da economia, por diferenciarem-se do Estado e do mercado, em que a sociedade civil possui o sentido de "público", porém "não estatal" (MOTTA, 2012). Apresentam um sentido de sociedade civil dissociada do Estado, que trava uma luta pela hegemonia do mercado na educação das classes populares, através do discurso da responsabilidade social.

As OSC assumiram papel de protagonismo na formação para o trabalho de jovens em cumprimento de medida socioeducativa de semiliberdade, oferecendo cursos de capacitação profissional, em sua maioria de livre oferta, e, de baixo custo para as instituições. Apesar de serem cursos idealizados para atingir as parcelas mais pobres da classe popular, os jovens autores de ato infracional dificilmente conseguiram acessar esses mesmos cursos antes de entrarem

\footnotetext{
${ }^{16}$ Inclui pessoa jurídica de direito privado sem fins lucrativos, que os aplica seus excedentes integralmente na consecução do respectivo objeto social; as sociedades cooperativas e as organizações religiosas que se dediquem a projetos de interesse público e cunho social (BRASIL, 2014 , art. $\left.2^{\circ}, \mathrm{I}, \mathrm{a}, \mathrm{b}, \mathrm{c}\right)$.
} 
no sistema socioeducativo, pois fazem parte daquela parcela da população em que as políticas públicas, mesmo que precárias, não estão acessíveis.

As parcerias firmadas com o Sistema $\mathrm{S}$ não possuem a expressividade esperada, já que as instituições vinculadas a esse sistema possuem a obrigação de garantir vagas em cursos profissionalizantes e no jovem aprendiz (BRASIL, 2012, art. 76; 77; 78; 79; 80). Apesar disso, apenas três CRIAADs possuem jovens realizando formação profissional, através do Sistema $S$, sendo que um dos cursos é o de garçom e ocorre no interior de uma das unidades, atendendo a 19 jovens. Em uma das unidades o jovem conseguiu a gratuidade no Projeto Capacitar e em relação ao outro jovem não foi possível saber se possuía bolsa integral ou se precisou pagar a mensalidade do curso.

O Sistema $S$ não integra a administração pública direta ou indireta, sendo composto por entidades que prestam serviços privados, mas de interesse público, recebendo incentivos financeiros do Estado. Frigotto (2010) questiona a utilização de recursos públicos por essa instituição sem que realmente haja interesse público, pois há cobrança de mensalidades nos cursos profissionalizantes, com poucas bolsas de gratuidade.

Através da análise dos relatórios também foi possível cartografar as experiências dos jovens aprendizes que cumprem a medida socioeducativa de semiliberdade no estado do Rio de Janeiro. A atenção das unidades socioeducativas para o Programa Jovem Aprendiz diz respeito a buscar despertar o interesse dos jovens em cumprimento de medida socioeducativa por uma atividade que possibilitaria a formação profissional remunerada e que garantisse a inserção em uma ocupação formal e incentivasse a continuidade do processo escolarização.

De 841 jovens que constam nos relatórios pedagógicos das unidades de semiliberdade de março a maio de 2019, apenas quatro encontravam-se participando do programa, todos na região metropolitana. Dos quatro jovens aprendizes indicados nos relatórios pedagógicos, apenas um não se encontrava no ensino médio, desenvolvendo atividade de trabalho no Bob's ${ }^{17}$, apesar da Lei de Aprendizagem garantir vagas no Programa para jovens do ensino fundamental também.

O jovem aprendiz deve estar cursando o ensino fundamental ou médio, com prioridade aos que se encontram em situação de vulnerabilidade, dentre eles os "adolescentes egressos do sistema socioeducativo ou em cumprimento de medidas socioeducativas" (BRASIL, 2018, art. 66, $\$ 5^{\circ}$ ). Contudo, a maior queixa é de que quase não há oportunidades para os jovens de baixa escolarida-

\footnotetext{
${ }^{17}$ Empresa de Fast Food com franquias em vários países.
} 
de, que são a grande maioria dos jovens em cumprimento de medida socioeducativa.

Dessa forma, diante de todas as questões aqui levantadas sobre a realidade nas unidades socioeducativas de semiliberdade, observamos que as condições de profissionalização apontam para possibilidades precárias de preparação dos jovens ao mundo do trabalho, estando distantes de cumprir o estabelecido na legislação vigente para os jovens em cumprimento de medida socioeducativa.

\section{Considerações finais}

As reformas materializadas no período de democratização do país, após a ditadura civil militar iniciada em 1964, ganharam características de construção de uma nova mentalidade com base na doutrina da proteção integral. Contudo, no contexto de neoliberalismo, as desigualdades sociais foram tomando proporções preocupantes e não permitiram que as reformas representassem o avanço na garantia dos direitos de crianças e jovens mais pobres.

O SINASE e os documentos oficiais do DEGASE recebem a influência da teoria do capital social, mantendo as bases ideológicas da teoria do capital humano. Dessa forma, direciona-se os investimentos em educação para os que ainda possuem qualificações competitivas e necessárias para o trabalho complexo. Contudo, é possível a inclusão dos jovens das classes subalternas, a grande maioria dos que se encontram no sistema, promovendo-se a cooperação e a confiança em instituições mercantilizadas que oferecem capacitação profissional de curta duração e de baixo custo.

De acordo com o SINASE, a formação profissional dos jovens em cumprimento de medida socioeducativa deve ser ofertada no âmbito da educação profissional, através dos cursos de formação inicial e continuada e, também da educação profissional técnica de nível médio e ou através de inserção no ensino superior. No entanto, evidenciamos que o estado do Rio de Janeiro não consegue cumprir essa proposta, pois os cursos ofertados aos jovens em semiliberdade visam à capacitação para o trabalho, de forma paralela à escolarização.

Assim, observamos no DEGASE, o reflexo do projeto de profissionalização para as classes populares no Brasil. Desde sempre, a formação profissional para as famílias pobres no Brasil esteve voltada para o trabalho simples, através de educação elementar acrescida de capacitação aligeirada e pouco custosa. Ao passo que, para as classes dominantes caberia à educação profissional 
especializada, custosa e prolongada, para o exercício do trabalho intelectual, fundamental para a compreensão do mundo do trabalho em sua totalidade (COSTA, 2019).

Consideramos que é fundamental uma educação profissional para os jovens em cumprimento de medida socioeducativa que ofereça o preparo teórico e prático para que estes se tornem trabalhadores e futuros trabalhadores e que a educação vá além das demandas de mercado e consumo. Para isso, é preciso compreender as dificuldades da sociedade atual sem perder a esperança na construção de oportunidades de crescimento através de uma educação crítica e emancipadora.

Olhando para atrás, reconhecemos importantes avanços na implementação da política socioeducativa no Brasil, principalmente nos marcos legais que reconhecem a proteção integral como política às crianças e jovens; porém, por outro lado, analisando os marcos operacionais, ou seja, a política em desenvolvimento, muito ainda precisamos avançar, sendo fundamental implementar ações que concretamente possibilitarão uma mudança na realidade social dos jovens em cumprimento de medida socioeducativa e, consequentemente, da sociedade em geral, principalmente de grande parcela que vive à margem das riquezas geradas no país.

\section{Referências}

BAZÍLIO, L. C. Trabalho, formação profissional e educação do adolescente. Perspectiva, Florianópolis, v. 14, n. 26, p. 203-220, jul./dez. 1996.

BRASIL. Lei $\mathbf{n}^{\circ}$ 8069/1990, de 13 de julho de 1990. Dispõe sobre o Estatuto da Criança e do Adolescente e dá outras providências. Brasília, DF, Diário Oficial da União, 16 de jul. 1990. Seção 1, p. 13563.

Lei $\mathrm{n}^{\circ}$ 9.394/1996, de 20 de dezembro de 1996. Estabelece a Lei de Diretrizes e Bases da Educação Nacional - LD.Brasília, DF. Diário Oficial da União, 23 dez. 1996, Seção I, p. 27833.

Lei $\mathrm{n}^{\circ} \mathbf{1 2 . 5 9 4}$, de 18 de janeiro de 2012. Institui o Sistema Nacional de Atendimento socioeducativo (SINASE).Brasília, DF, Diário Oficial da União, 19 jan. 2012, Seção I, p.3.

Lei $\mathrm{n}^{\circ}$ 13.019, de 31 de julho de 2014, Brasília, DF, Diário Oficial da União, 01 agos.2014, Seção 1, p.1. 
Decreto $\mathrm{n}^{\circ} \mathbf{9 . 5 7 9}$, de 22 de novembro de 2018. Brasília. 2018. Diário Oficial da União, 23 nov. 2018, Seção 1, p. 49.

BRASIL. Constituição (1988). Constituição da República Federativa do Brasil. Brasília, DF: Supremo Tribunal Federal, 2019.

CÂMARA, R. J. Agênese das primeiras escolas no Departamento Geral de Ações Socioeducativas do Rio de Janeiro (DEGASE/RJ): uma escolarização suigeneres (1994-2001). 2017. 136 f. Dissertação (Mestrado em Educação) Faculdade de Educação, Universidade Federal do Rio de Janeiro, Rio de Janeiro, 2017.

CONANDA. [SINASE (2006)]. Resolução no 119, de 11 de dezembro de 2006. In: DEGASE. Socioeducação: legislações, normativas e diretrizes nacionais e internacionais. Rio de Janeiro: Novo Degase, v.2, 2013.

COSTA, A.C. Socioeducação: Estrutura e funcionamento da comunidade educativa. Brasília: Secretaria Especial dos Direitos Humanos, 2006.

COSTA, D. D. H. F. da. Lei Nacional da Aprendizagem Profissional: problematizações de uma política em disputa no mercado da formação profissional. 2019. 175 p. Dissertação (Mestrado em Educação) - Faculdade de Educação, Universidade Federal Fluminense, Niterói, 2019.

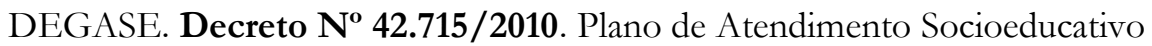
do Governo do Estado do Rio de Janeiro - PASE. Rio de Janeiro: DEGASE, 2010a.

Projeto Político Institucional - PPI. In: Socioeducação: legislações, normativas e diretrizes nacionais e internacionais. Rio de Janeiro: DEGASE, v. 2, 2010b.

FIDALGO, F. e MACHADO, L. Dicionário da Educação Profissional. Belo Horizonte: UFMG, 2000.

FRIGOTTO, G. A produtividade da escola improdutiva: um (re)exame das relações entre educação e estrutura econômico-social capitalista. 9. ed. São Paulo: Cortez, 2010.

GODOI, R. S. Juventude e espaço público: jovens do sistema socioeducativo e o direito à cidade. In: JULIÃO, E. F. Trajetórias de vida de jovens em situação de privação de liberdade: um estudo sobre a delinquência juvenil no estado do Rio de Janeiro. Jundiaí/SP: Paco Editorial, 2019. p. 173-192. 
JESUS, I. M. Escolarização de jovens de 15 a 17 anos em situação de privação de liberdade: reflexões sobre o sistema socioeducativo do estado do Rio de Janeiro. 2018. Dissertação (Mestrado em Educação) - Faculdade de Educação, Universidade Federal Fluminense, Niterói, 2018.

JULIÃO, E. F.; OLIVEIRA, V. Sistema de garantia de direitos: Questões e perspectivas para uma política socioeducativa. In: ZAMORA, M. H.; OLIVEIRA, M. C. L. de (Org.). Perspectivas interdisciplinares sobre adolescência, socioeducação e direitos humanos. 1. ed. Curitiba: Appris, 2017, Seção 1, cap. 3, 293 p.

MOTTA, V. Ideologia do capital social: atribuindo uma face mais humana ao capital. Rio de Janeiro: EdUERJ, 2012.

MPMG. Comentários à Lei no 12.594/2012: Sistema Nacional de Atendimento Socioeducativo. In: Jurídico: Revista do Ministério Público do Estado de Minas Gerais. Minas Gerais: CEAF, 2014.

NOVELLINO, M. S. F. OLIVEIRA, L. A. V. Territórios: rede do crime organizado no Rio de Janeiro. In: XVII ENAMPUR, , 2019, Natal. Anais [XVIII ENANPUR 2019] Natal: EDUFRN, 2019. p. 1-23.

PAIVA, J. Os sentidos do direito à educação para jovens e adultos. Petrópolis: DP et Alii; Rio de Janeiro: FAPERJ, 2009.

PEREIRA, I.; GOMES, M. do R. C. de S. Gestão da política socioeducativa ao adolescente em conflito com a lei. In: ZAMORA, M. H.; OLIVEIRA, M. C. L. de (Org.). Perspectivas interdisciplinares sobre adolescência, socioeducação e direitos humanos. 1. ed. Curitiba: Appris, 2017.

SOUSA, L. P. de; GUEDES, D. R. A desigual divisão sexual do trabalho: um olhar sobre a última década. Estudos avançados, São Paulo, v. 30, n. 87, p.123-139, mai./ago. 2016.

RODRIGUES, E. A justiça juvenil no Brasil e a responsabilidade penal do adolescente: rupturas, permanências e possibilidades, 1. ed. Rio de Janeiro: Revan, 2017.

RUMMERT, S. M.; ALGEBAILE, E.; VENTURA, J. Educação da classe trabalhadora brasileira: expressão do desenvolvimento desigual e combinado. Revista Brasileira de Educação, Rio de Janeiro, v. 18, n. 54, p.717-799, jul./set. 2013. 